\title{
Inhibitory effects of the ethanol extract of Gleditsia sinensis thorns on human colon cancer HCT116 cells in vitro and in vivo
}

\author{
SE-JUNG LEE ${ }^{1,2}$, YOUNG-HWA CHO ${ }^{3}$, HEEJONG KIM ${ }^{3}$, KEERANG PARK $^{3}$, \\ SUNG-KYU PARK ${ }^{4}$, SANG-DO HA ${ }^{2}$, WUN-JAE KIM ${ }^{5}$ and SUNG-KWON MOON ${ }^{1}$
}

\author{
${ }^{1}$ Department of Food and Biotechnology, Chungju National University, Chungju, Chungbuk 380-702; \\ ${ }^{2}$ Department of Food Science and Technology, Chung-Ang University, Ansung 72-1; ${ }^{3}$ Department of Biotechnology, \\ Juseong College, Chungbuk 363-794; ${ }^{4}$ Seoul Metropolitan Government, Institute of Public Health and Environment; \\ ${ }^{5}$ Department of Urology, Chungbuk National University College of Medicine, Cheongju, Chungbuk 361-763, Korea
}

Received June 5, 2009; Accepted July 29, 2009

DOI: 10.3892/or_00000594

\begin{abstract}
The thorns of Gleditsia sinensis have traditionally been used in the treatment of several diseases, which includes their use as anti-tumor agents, but there has been no scientific evidence of this anti-tumor effect. However, the present study has identified a novel mechanism for the anti-tumor effect of Gleditsia sinensis thorns in the treatment of colon cancer. Treatment with the ethanol extract of Gleditsia sinensis thorns (EEGS) resulted in significant growth inhibition together with $\mathrm{G} 2 / \mathrm{M}$-phase cell cycle arrest at a dose of $600 \mu \mathrm{g} / \mathrm{ml}\left(\mathrm{IC}_{50}\right)$ in HCT116 cells. In addition, treatment with EEGS induced p27 expression and down-regulated expression of cyclins and cyclin-dependent kinases. Moreover, EEGS treatment induced phosphorylation of extracellular signal-regulated kinases (ERK), p38 MAP kinase and JNK (c-Jun N-terminal kinases). Among the pathways examined, only PD98059 (ERK-specific inhibitor) abolished EEGS-dependent p27 expression. Similarly, suppression of ERK function reversed EEGS-mediated cell proliferation inhibition and decreased cell cycle proteins. In addition, tumor necrosis factor- $\alpha$ (TNF- $\alpha$ )induced matrix metalloproteinase-9 (MMP-9) expression was inhibited by EEGS treatment via decreased transcriptional activity of both activator protein-1 (AP-1) and nuclear factor$\kappa B$. Finally, EEGS treatment significantly reduced tumor sizes in HCT116 cell-xenografted tumor tissues, which was associated with the changed levels of ERK phosphorylation, p27 and MMP-9 expression. Overall, these results have identified a novel molecular mechanism for EEGS in the
\end{abstract}

Correspondence to: Dr Sung-Kwon Moon, Department of Food and Biotechnology, Chungju National University, 123 Geomdan-ri Iryu-myeon, Chungju, Chungbuk 380-702, Korea

E-mail:skmoon@cjnu.ac.kr

Key words: Gleditsia sinensis thorns, colon cancer, extracellular signal-regulated kinases, G2/M phase cell cycle arrest, p27, matrix metalloproteinase-9 treatment of colon cancer and might provide a theoretical basis for the potential therapeutic use of EEGS in the treatment of malignancies.

\section{Introduction}

Colorectal cancer is one of the most common malignancies in the world (1). Although intensive research during the past few years has led to considerable improvement in treatment and diagnosis at an early stage, the prognosis remains dire. In general, genetic defects, such as mutation in adenomatous polyposis coli (APC) and a loss in tumor suppressor gene p53, have been widely studied in colon cancer progression $(2,3)$. Previous studies have shown that epigenetic alterations controlling tumor cell proliferation, apoptosis and migration are associated with colon cancer growth and progression (4-6). Uncontrolled tumor cell proliferation activity is usually involved in aberrant cell-cycle progression (3). The role of numerous molecular factors, including extracellular signalregulated kinases (ERK), matrix metalloproteinase-9 (MMP-9), nuclear factor- $\mathrm{KB}(\mathrm{NF}-\kappa \mathrm{B})$ and activator protein-1 (AP-1), have been implicated in the progression of colon cancer (4-7). These studies suggest that agents that could overcome these epigenetic defects could be potentially effective in controlling the growth of colon cancer. Recently, the use of medicinal plants in the development of anti-tumor agents in scientific and industrial communities has become a good chemo-preventive regimen with few side effects (8).

Gleditsia sinensis, a perennial shrub, has been used in traditional medicine for the treatment of swelling, suppuration, carbuncle and skin diseases in oriental countries for years (9). Some constituents of Gleditsia sinensis (stigmasterol, ellagic acid glycoside and lupine acid) have multiple pharmacological effects, such as anti-mutagenetic (10), anti-microbial (11) and anti-HIV activity (12). Its crude extract showed anti-allergenic (13) and anti-inflammatory effects (14). However, scientific evidence remains unclear for support of the anti-tumor effect of the extract of Gleditsia sinensis thorns, although the fruit extract of Gleditsia sinensis has been credited with tumor growth inhibition in several cell lines $(15,16)$. The present study is the first report of the anti-tumor effect of Gleditsia 
sinensis thorns on a relevant pathway between the cell cycle regulation and signaling pathways involved in growth inhibition and MMP regulation in human colon cancer HCT116 cells in vitro. Moreover, in vivo efficacy of ethanol extract of Gleditsia sinensis thorns were examined, using a human colon cancer xenograft model.

\section{Materials and methods}

Materials. Polyclonal antibodies to cyclin B1, pCdc2, Cdc2, pCdc25c and Cdc25c were obtained from Santa Cruz (Santa Cruz, CA). Polyclonal antibodies to p21WAF1, p53, p27, ERK, phospho-ERK, p38 MAP kinase, phospho-p38 MAP kinase, JNK and phospho-JNK were obtained from New England Biolabs. PD98059, SP600125 and SB203580 were obtained from Calbiochem (San Diego, CA). A polyclonal antibody to MMP-9 was obtained from Chemicon.

Preparation of extract. Air-dried and crushed Gleditsia sinensis thorns $(100 \mathrm{~g})$ were added to ethanol and extraction was performed by heating at $100^{\circ} \mathrm{C}$. The extract was then concentrated with a rotary evaporator and lyophilized. The final extract, weighing $10 \mathrm{~g}$ (a collection rate of 10\%), was diluted with saline solution.

Animal care. All mice were purchased from SLC Inc., Japan, and maintained for seven days prior to treatment. Animals were grouped for different types of treatments in a random manner and five mice per cage were housed in polycarbonate cages with hardwood bedding (JRS Lignocel FS-14, Jung Ang Lab Animal Inc., South Korea). Mice were fed freely Dyets of AIN-76A Rodent Purified Diet (Jung Ang Lab Animal Inc.). The animal rooms were maintained as follows: a 12-h light/dark fluorescent light cycle, a minimum of 10 room air changes per hour, $21-24$ and $35-65^{\circ} \mathrm{C}$ relative humidity. All animal experiments were performed in accordance with the Standard Operation Procedures of Laboratory Animals and were approved by the Institutional Animal Care and Use Committee (IACUC) of the Laboratory Animal Research Center at Chungbuk National University (Approval number CBNURA-047-0902-01).

Cell cultures. The human colon cancer cell line HCT116 was obtained from the American Type Culture Collection. The cells were maintained in DMEM (4.5 g glucose/liter) supplemented with $10 \%$ fetal calf serum, L-glutamine and antibiotics (Biological Industries, Beit Haemek, Israel) at $37^{\circ} \mathrm{C}$ in a $5 \% \mathrm{CO}_{2}$ humidified incubator.

Cell viability assay. Subconfluent, exponentially grown HCT116 cells in 24-well plates, were incubated with ethanol extract of Gleditsia sinensis thorns (EEGS) for various lengths of time. Cell viability was determined using a modification of 3-(4,5-dimethylthiazol-2-yl)-2,5-diphenyltetrazolium bromide (MTT) assay, which is based on the conversion of the tetrazolium salt 3-(4,5-dimethylthiazol-2-yl)-5-(3carboxymethoxyphenyl)-2-(4-sulfophenyl)-2-tetrazolium to the formazan product by mitochondrial dehydrogenase (17). The formazan product was quantified by measuring absorbance at $490 \mathrm{~nm}$.
Apoptosis detection by ELISA. This method is based on the quantification of the enrichment of mono- and oligonucleosomes in the cytoplasm using a Cell Death Detection ELISA kit (Roche; Mannheim, Germany). Briefly, after treatment of cells with EEGS, the cells were lysed and centrifuged. The supernatant containing the cytoplasmic histone-associated DNA fragments was transferred to a microplate coated with streptavidin, and was then reacted with a mixture of the anti-histone antibodies labeled with biotin and anti-DNA antibodies coupled with peroxidase. The substrate of peroxidase was thereafter added and development of the color was read photometrically at 405 with $490 \mathrm{~nm}$ as the background. The specific enrichment of mono- and oligonucleosomes released into the cytoplasm was expressed as an enrichment factor compared with the control.

Cell cycle analysis (FACS). Cells were harvested, fixed in 70\% ethanol and stored at $-20^{\circ} \mathrm{C}$. Cells then were washed twice with ice-cold PBS and incubated with RNase and the DNA intercalating dye, propidium iodide. Cell cycle phase analysis was performed using a Becton-Dickinson Facstar flow cytometer equipped with Becton-Dickinson cell fit software.

Immunoprecipitation and immunoblotting. Growth-arrested cells were treated with EEGS in the presence of $10 \%$ FBS for various durations at $37^{\circ} \mathrm{C}$. Cell lysates were prepared and immunoprecipitation and immunoblotting were performed, as previously described (17).

Zymography. The conditioned medium was electrophoresed in a polyacrylamide gel containing gelatin a concentration of $1 \mathrm{mg} / \mathrm{ml}$. The gel was washed at room temperature for $2 \mathrm{~h}$ with $2.5 \%$ Triton $\mathrm{X}-100$ and then at $37^{\circ} \mathrm{C}$ overnight in a buffer containing $10 \mathrm{mM} \mathrm{CaCl}_{2}, 150 \mathrm{mM} \mathrm{NaCl}$ and $50 \mathrm{mM}$ Tris- $\mathrm{HCl}$ ( $\mathrm{pH}$ 7.5). The gel was stained with $0.2 \%$ Coomassie blue and photographed on a light box. Proteolysis was detected as a white zone in a dark blue field.

Creation of MMP-9 promoter reporter construct. A $0.7-\mathrm{kb}$ segment in the 5'-flanking region of the human MMP-9 gene was amplified by PCR using primers specific for the human MMP-9 gene (Accession No. D10051): 5'-ACATTTGCCCG AGCTCCTGAAG (forward/SacI) and 5'-AGGGGCTGCCA GAAGCTTATGGT (reverse/HindIII). The pGL2-Basic vector containing a polyadenylation signal upstream from the luciferase gene was used to construct the expression vectors by subcloning PCR-amplified DNA for the MMP-9 promoter into the SacI/HindIII site of the pGL2-Basic vector (18). The size of the PCR products was confirmed by electrophoresis and by DNA sequencing.

Transient transfection. Each plasmid was transfected into cells using Superfect reagent (Qiagen, Valencia, CA) according to the manufacturer's instructions. Luciferase activity was measured using a luciferase assay system (Promega, Madison, WI) according to the manufacturer's instructions. Firefly luciferase activity was standardized to ß-galactosidase activity.

Nuclear extracts and electrophoretic mobility shift assay. Nuclear extracts were essentially prepared as described 
elsewhere (18). Cultured cells were collected by centrifugation, washed and suspended in a buffer containing $10 \mathrm{mM}$ Hepes (pH 7.9), 10 mM KCl, 0.1 mM EDTA, 0.1 mM EGTA, 1 mM DTT and $0.5 \mathrm{mM}$ PMSF. After $15 \mathrm{~min}$ on ice, the cells were vortexed in the presence of $0.5 \%$ nonidet NP-40. The nuclear pellet was then collected by centrifugation for $15 \mathrm{~min}$ at $4^{\circ} \mathrm{C}$ and extracted in a buffer containing $20 \mathrm{mM}$ Hepes (pH 7.9), 0.4 M NaCl, 1 mM EDTA, 1 mM EGTA, 1 mM DTT and $1 \mathrm{mM}$ PMSF.

The nuclear extract $(10-20 \mu \mathrm{g})$ was preincubated at $4^{\circ} \mathrm{C}$ for $30 \mathrm{~min}$ with a 100-fold excess of an unlabeled oligonucleotide spanning the -79 MMP-9 cis element of interest. The sequences were as follows: AP-1, CTGACCCCTGAGT CAGCACTT; and NF-кB, CAGTGGAATTCCCCAGCC. The reaction mixture was then incubated at $4^{\circ} \mathrm{C}$ for $20 \mathrm{~min}$ in a buffer [25 mM Hepes buffer ( $\mathrm{pH} 7.9), 0.5 \mathrm{mM}$ EDTA, $0.5 \mathrm{mM}$ DTT, $0.05 \mathrm{M} \mathrm{NaCl}$ and $2.5 \%$ glycerol] with $2 \mu \mathrm{g}$ of poly $\mathrm{dI} / \mathrm{dC}$ and $5 \mathrm{fmol}\left(2 \times 10^{4} \mathrm{cpm}\right)$ of a Klenow end-labeled [ $\left.{ }^{32} \mathrm{P}-\mathrm{ATP}\right]$ 30-mer oligonucleotide, spanning the DNA-binding site of the MMP-9 promoter. The reaction mixture was electrophoresed at $4^{\circ} \mathrm{C}$ in a $6 \%$ polyacrylamide gel using a TBE ( $89 \mathrm{mM}$ Tris, $89 \mathrm{mM}$ boric acid and $1 \mathrm{mM}$ EDTA) running buffer. The gel was rinsed with water, dried and exposed overnight to X-ray film.

In vivo efficacy of EEGS on tumor growth using a xenograft mouse model. To determine in vivo anti-cancer efficacy of EEGS on tumor growth, a xenograft mouse model was established by implantation with human colon cancer cells, HCT116 ( $1 \times 10^{7}$ cells/mouse), to BABL/c nude mice. The experiment was composed of 6 test groups and 2 control groups. There were 10 mice per group. After the implantation of tumor cells into the mice, the nude mice were daily administrated various concentrations of Gleditsia sinensis extract by an oral injection. The body weights and the volume of tumor masses in the mice were measured every 2-3 days and the general body condition of the mice was also carefully observed daily. The negative control mice were injected with a saline solution and the mice in the positive control group were daily treated with $350 \mathrm{mg} / \mathrm{kg}$ of Xeloda, one of the best anti-cancer drugs (Roche, Switzerland) for 2 weeks, followed by 10 days of no treatment. At the end of experiment, the treated mice were euthanized to isolate tumor masses, which were then weighed. The final volume of each isolated tumor mass was also measured.

Statistical analysis. Where appropriate, data were expressed as mean \pm SE. Data were analyzed using factorial ANOVA and Fisher's least significant difference test where appropriate. Statistical significance was set at $\mathrm{P}<0.05$.

\section{Results}

EEGS reduces the proliferation of human colon cancer HCT116 cells. To examine the inhibitory effect of EEGS on the proliferation of colon cancer cells, HCT116 cells were incubated in the absence or presence of various concentrations of EEGS $(0-1000 \mu \mathrm{g} / \mathrm{ml})$ for $24 \mathrm{~h}$. EEGS showed a significant inhibitory effect on the growth of HCT116 cells in a concentration-dependent manner (Fig. 1A). The vehicle
A.

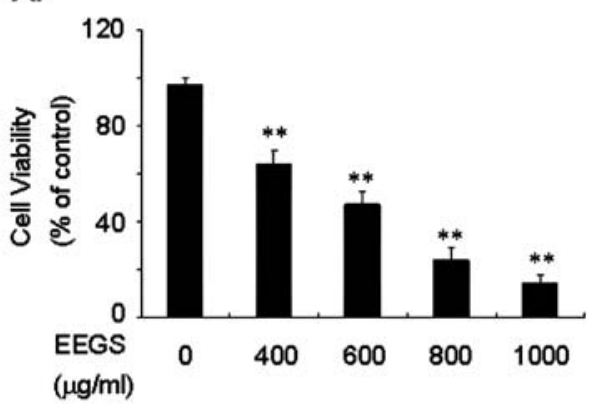

B.

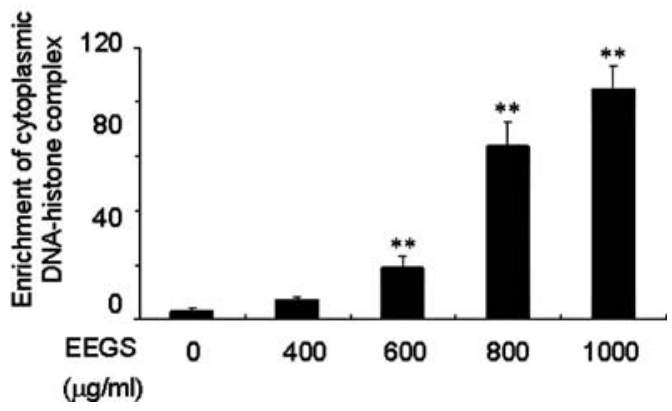

Figure 1. EEGS suppressed cell proliferation and induced apoptosis in HCT116 cells. (A) Subconfluent, exponentially growing cells were incubated with EEGS for $24 \mathrm{~h}$ at indicated concentrations in $10 \%$ DMEM. Cell viability was determined by using a modification of the MTT assay. (B) Detection of apoptosis in cells treated with EEGS. HCT116 cells were incubated in $10 \%$ serum medium, followed by addition of EEGS and culture for $24 \mathrm{~h}$. Cytoplasmic DNA-histone complex was measured by ELISA. Results are presented as mean \pm SE from three triplicate experiments. ${ }^{* *} \mathrm{P}<0.01$ compared with no EEGS treatment.

(ethanol) had no effect on the basal levels of cell viability (data not shown). In addition, we used an ELISA-based assay (see Materials and methods) to measure EEGS-induced apoptosis. As shown in Fig. 1B, using a quantitative assay, EEGS in high concentrations $(>800 \mu \mathrm{g} / \mathrm{ml})$ significantly increased the cytoplasmic DNA-histone complex in HCT116 cells.

EEGS-induced G2/M-phase cell cycle arrest. To investigate whether the retarded cell growth was due to cell-cycle arrest, cell cycle analysis was performed by flow cytometry. After EEGS treatment for $24 \mathrm{~h}$, HCT116 cells increased DNA content of the $\mathrm{G} 2 / \mathrm{M}$ phase at the concentration of $600 \mu \mathrm{g} / \mathrm{ml}$, as compared with the control (Fig. 2A-E). To determine the mechanisms underlying the $\mathrm{G} 2 / \mathrm{M}$ arrest that were observed after addition of EEGS, we next applied the effect of EEGS treatment on the molecules involved in the G2/M phase of the cell cycle. As shown in Fig. 3A, EEGS treatment of cells strongly decreased the expression of pCdc25c (Ser216), Cdc25c, pCdc2 (Tyr15) and Cdc2 protein levels. Similar EEGS treatment also resulted in a strong decrease in cyclin B1 protein levels in HCT116 cells (Fig. 3A).

EEGS-induced cell cycle arrest is associated with upregulation of $p 27$. Immunoblotting was performed to study the effect of EEGS on the cell cycle inhibitors, which were involved in cell cycle progression at the $\mathrm{G} 2 / \mathrm{M}$ phase transition checkpoint (19-21). Treatment of HCT116 cells with EEGS resulted in a significant dose-dependent induction of p 27 
A.

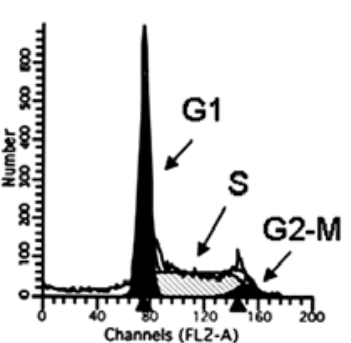

C.

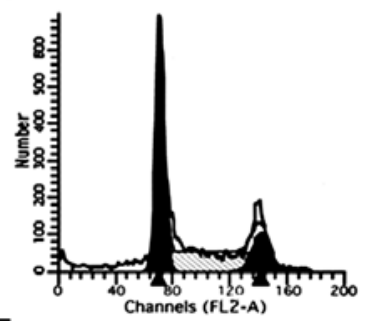

E.

\begin{tabular}{cccc}
\hline & G0/G1 & $S$ & G2M \\
\hline (A) Control & 48.71 & 44.43 & 6.86 \\
(B) EEGS $(400 \mu \mathrm{g} / \mathrm{ml})$ & 45.36 & 45.03 & 5.22 \\
(C) EEGS $(600 \mu \mathrm{g} / \mathrm{ml})$ & 46.31 & 37.59 & 16.09 \\
(D) EEGS $(800 \mu \mathrm{g} / \mathrm{ml})$ & 46.96 & 36.75 & 17.00 \\
\hline
\end{tabular}

Figure 2. EEGS induces G2/M cell cycle arrest in HCT116 cells. Cells were treated with 0 (A), 400 (B), 600 (C) and $800 \mu \mathrm{M}$ EEGS (D). Cells were subjected to flow cytometric analysis to determine the effect of EEGS on cell-cycle distribution. (E) The percentage of cells in each population is shown as the mean $\pm \mathrm{SE}$ from three triplicate experiments.

compared with untreated cells (Fig. 3B). However, EEGS had no effect on the induction of $\mathrm{p} 21$ and $\mathrm{p} 53$ tumor suppressor proteins, suggesting that it is likely that $\mathrm{p} 21$ and $\mathrm{p} 53$ were not involved in the EEGS-induced cell cycle arrest (Fig. 3B).

Next, the effects of EEGS on the association between p27 and CDKs were examined. To assess the effect of EEGS on this protein-protein interaction, cell extracts were subjected to immunoprecipitation using anti-Cdc2 antibody. After SDSPAGE and blotting, membranes were probed with anti-p27. In EEGS-treated cells, the level of Cdc2/p27 complex was increased (Fig. 3C).

Effects of EEGS on ERK, JNK and p38 MAP kinase activation in HCT116 cells. To determine whether MAP kinase activation including ERK1/2, JNK and p38 MAP kinase, was involved in EEGS-induced inhibition of cell growth, immunoblotting was performed. As shown in Fig. 4, EEGS increased the amount of phosphorylated ERK1/2, JNK and p38 MAP kinase at 1,3 and $6 \mathrm{~h}$. Phosphorylation of the MAP kinases (ERK1/2, p38 MAPK and JNK) induced by EEGS was inhibited by specific kinase inhibitors, such as PD98059, SB203580 and SP600125 (data not shown). These results suggest that EEGS inhibits cell growth via activation of the ERK1/2, JNK and p38 MAP kinase pathways.

EEGS-induced p27 is blocked by PD98059, a specific inhibitor of ERK. To confirm the role of MAP kinase in EEGS-induced
A.

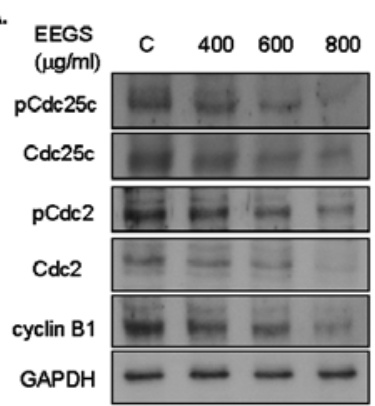

B.

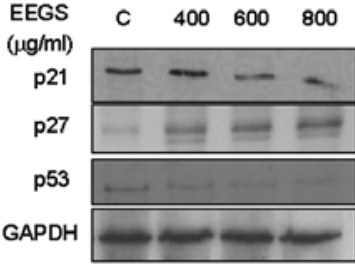

c.

$\begin{array}{llll}C & 400 & 600 & 800\end{array}$

$\alpha \mathrm{Cdc} 2 / \mathrm{p} 27$

IP: anti-Cdc2

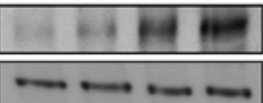

Figure 3. EEGS-induced cell cycle arrest is associated with up-regulation of p27 in HCT116 cells via a p53-independent pathway. (A and B) 5637 cells were treated with naringin at the indicated concentrations and immunoblot analysis was performed with antibodies specific for cyclin B1, pCdc2, Cdc2, $\mathrm{pCdc} 25 \mathrm{c}$, and $\mathrm{Cdc} 25 \mathrm{c}, \mathrm{p} 21 \mathrm{WAF} 1, \mathrm{p} 27$ and $\mathrm{p} 53$. The results from representative experiments were normalized to GAPDH expression. (C) Equal amounts of cell lysates were subjected to immunoprecipitation with anti-Cdc2. The immunoprecipitates were examined by SDS-PAGE. After electrophoresis, the samples were transferred to a nitrocellulose membrane, followed by immunoblot analysis with an anti-p27 antibody. The results from representative experiments were normalized to immunoprecipitated Cdc 2 expression.

p27 induction, immunoblotting was undertaken using MAP kinase-specific kinase inhibitors. As shown in Fig. 5A, the EEGS-induced increase in $\mathrm{p} 27$ expression was reduced to the control level by PD98059 treatment. However, SP600125 and SB203580 had no apparent effect on EEGS-induced p27 levels. In addition, the protein levels of $\mathrm{Cdc} 25 \mathrm{c}$ and $\mathrm{Cdc} 2$ also were reversed after PD98059 treatment for 24 h (Fig. 5C).

EEGS-induced cell growth inhibition is reversed by ERK inhibition. To further investigate the involvement of ERK activation on EEGS-induced cell growth inhibition, we pretreated the cells with PD98059 and performed an MTT assay (Fig. 5B). HCT116 cells were pretreated for $40 \mathrm{~min}$ with or without $40 \mu \mathrm{M}$ PD98059, followed by treatment with $600 \mu \mathrm{g} / \mathrm{ml}$ EEGS in the presence of $10 \%$ serum. Treatment of HT116 cells with PD98059 abolished the EEGS-induced decrease of cell growth (Fig. 5B). However, SB203580 and SP600125 had no effect on EEGS-induced cell growth inhibition (data not shown), suggesting that the ERK signaling pathway in HCT116 cells is involved in EEGS-induced cell growth inhibition.

EEGS inhibits TNF- $\alpha$-induced MMP-9 expression via the decrease of $N F-\kappa B$ and $A P-1$ binding activities. Gelatin zymography was performed to examine the effect of EEGS on MMP-9 expression induced by TNF- $\alpha$. The results revealed that $\mathrm{TNF}-\alpha$ treatment increased the MMP-9 levels in HCT116 cells (Fig. 6A). Pretreatment of cells with EEGS significantly reduced TNF- $\alpha$-induced MMP-9 secretion in a dose-dependent manner (Fig. 6A). By contrast, constitutive MMP-2 expression causes no significant effect by either TNF- $\alpha$ or EEGS treatment (Fig. 6A). Immunoblot analysis showed similar results in HCT116 cells (Fig. 6A).

Next, promoter and gel-shift assays were used to clarify the mechanism by which EEGS is involved in the inhibition of MMP-9 expression. As shown in Fig. 6B, TNF- $\alpha$ treatment 


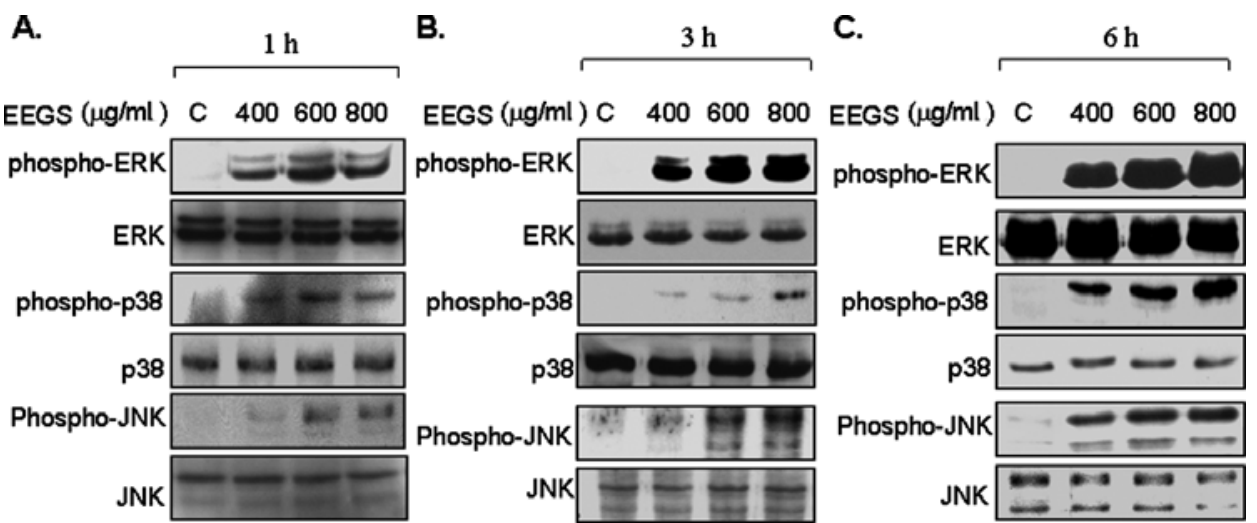

Figure 4. EEGS induced ERK1/2, JNK and p38 MAP kinase phosphorylation. HCT116 cells were treated with various EEGS at $1 \mathrm{~h}(\mathrm{~A}), 3 \mathrm{~h}$ (B) and $6 \mathrm{~h}$ (C). Then, cells were harvested, lysed and the phosphorylation levels of ERK1/2, JNK and p38 MAP kinase were detected by immunoblot analysis using antibodies phospho-specific for ERK1/2, JNK and p38 MAP kinase.

A.

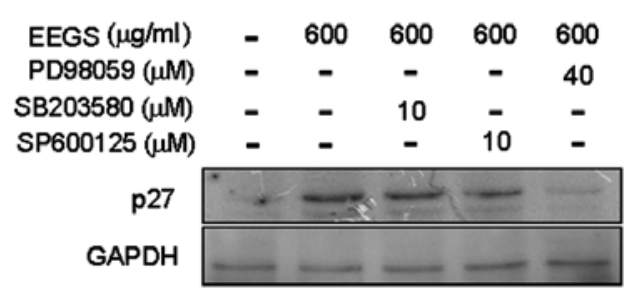

B.

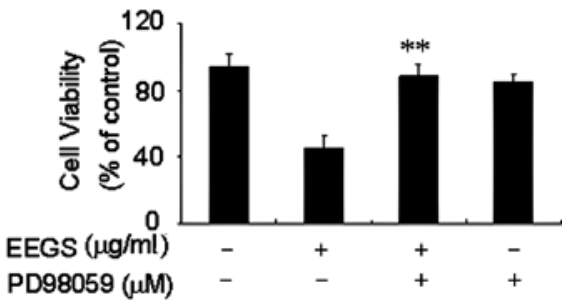

C.

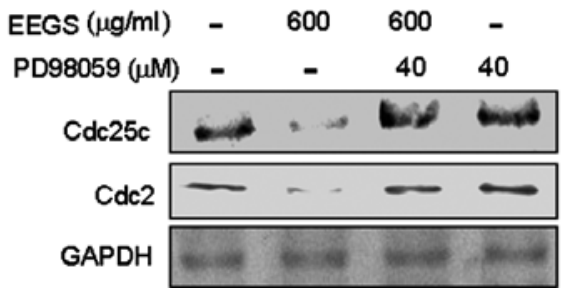

Figure 5. MEK1/2 inhibitor reversed p27 expression, decreased growth inhibition and G2/M-phase cell cycle-associated proteins by EEGS. (A and C) Cells were plated and were pre-incubated for $40 \mathrm{~min}$ in the absence or presence of PD98059 $(40 \mu \mathrm{M})$, SB203580 $(10 \mu \mathrm{M})$ and SP600125 $(10 \mu \mathrm{M})$. Cells were then treated with $600 \mu \mathrm{g} / \mathrm{ml}$ EEGS, followed by immunoblot analysis performed with antibodies specific for p27, Cdc2 and Cdc25c. The results from representative experiments were normalized to GAPDH expression. (B) Cells were pretreated for 40 min with $40 \mu \mathrm{M}$ PD98059 before treatment with $600 \mu \mathrm{g} / \mathrm{ml}$ EEGS at $24 \mathrm{~h}$. MTT assay were determined as described under Materials and methods. Indicated values are means of triplicate wells. ${ }^{* *} \mathrm{P}<0.01$ compared with EEGS treatment.

markedly induced MMP-9 promoter activity in HCT116 cells. Pretreatment of cells with EEGS inhibited TNF- $\alpha-$ induced MMP-9 promoter activity (Fig. 6B). To determine whether EEGS suppresses TNF- $\alpha$-induced MMP-9 expression through the regulation of transcription factors, a gel-shift assay was employed. As shown in Fig. 6C, TNF- $\alpha$ increased NF- $\mathrm{KB}$ and AP-1 binding activities in HCT116 cells. Pretreatment with EEGS inhibited TNF- $\alpha$-stimulated binding to both the NF-кB and AP-1 motifs.

EEGS suppressed the in vivo growth of HCT116 cells. To verify the anti-tumor effects of EEGS $(20,200,2000 \mathrm{mg} / \mathrm{kg})$ in vivo, gavage feeding of it was begun with nude mice at day 6 after the xenograft implantation. As shown in Fig. 7A and $\mathrm{B}$, for the mice treated with EEGS $(20 \mathrm{mg} / \mathrm{kg})$, the tumor volumes showed a $70 \%$ decrease as compared with the control. Compared with xeloda, in decreasing tumor volume, this effect showed an almost equivalent effect to that of a $20 \mathrm{mg} / \mathrm{kg}$ dose of EEGS (Fig. 7A and B). In addition, EEGS showed no side effects such as weight loss. To investigate whether the inhibition of tumor growth in vivo is accompanied by EEGS biomarkers during molecular analysis, the protein lysates were extracted from tumor tissues in each group and immunoblot analyses were performed. The content of ERK activation and p27 expression was increased in the tumor isolated from the EEGS-treated mice (Fig. 7C). In contrast, the expression of MMP-9 was down-regulated in the EEGS-treated tumor tissues.

\section{Discussion}

Although many anti-tumor agents have recently been developed and used, serious problems such as side effects and resistance must be overcome in the treatment of cancer (22). The application of oriental medicinal herbs, which have rich sources of potential cancer chemopreventive and therapeutic 
A.

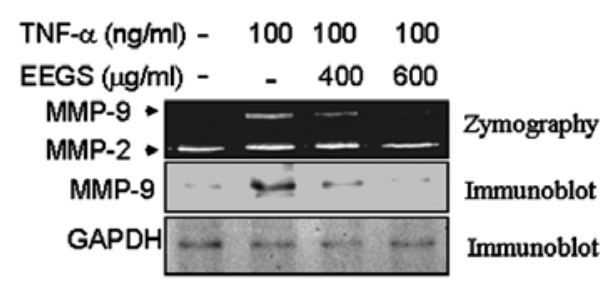

B.

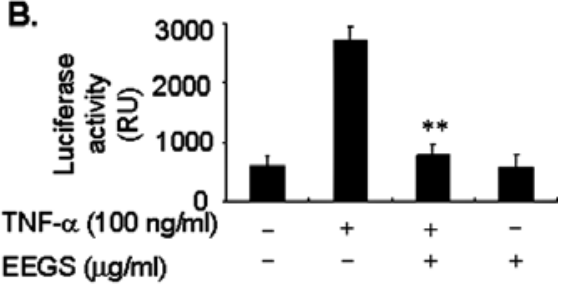

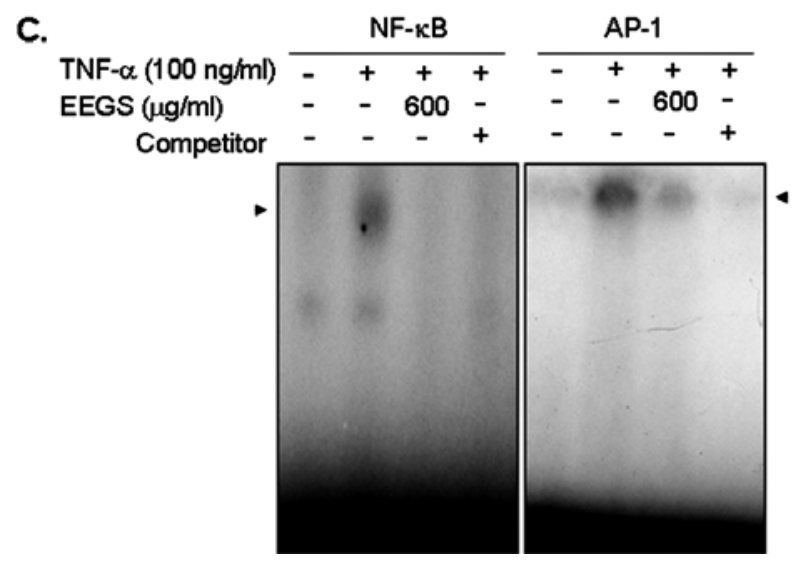

Figure 6. EEGS inhibits TNF- $\alpha$-induced MMP-9 expression through decreased DNA binding activity of NF-kB or AP-1 in the MMP-9 promoter in HCT116 cells. After a 1-day period of nutrient deprivation, cells were pretreated for 30 min with EEGS at the indicated concentrations $(\mu \mathrm{g} / \mathrm{ml})$ prior to stimulation with or without TNF- $\alpha(100 \mathrm{ng} / \mathrm{ml})$ for $24 \mathrm{~h}$ and then harvested. (A) The culture supernatants were analyzed zymographically for MMP activity. Similarly, immunoblot analysis was performed with antibodies specific for MMP-9. (B) Cells were transiently transfected with pGL2-MMP-9WT, which contained 710 bp of the 5'-promoter region of the MMP-9 gene and then were cultured with TNF- $\alpha(100 \mathrm{ng} / \mathrm{ml})$ in the presence or absence of EEGS at the indicated concentrations. Luciferase activity was determined from cell lysates as described in Materials and methods. ${ }^{* *} \mathrm{P}<0.05$ compared with TNF- $\alpha$ treatment. (C) Cells pretreated with the indicated concentrations of EEGS for $40 \mathrm{~min}$ in serum-free medium were incubated with TNF- $\alpha$ (100 ng/ml) for $24 \mathrm{~h}$. After incubation, nuclear extracts were analyzed for activated NF-kB or AP-1 using EMSA with radiolabeled oligonucleotide probes.
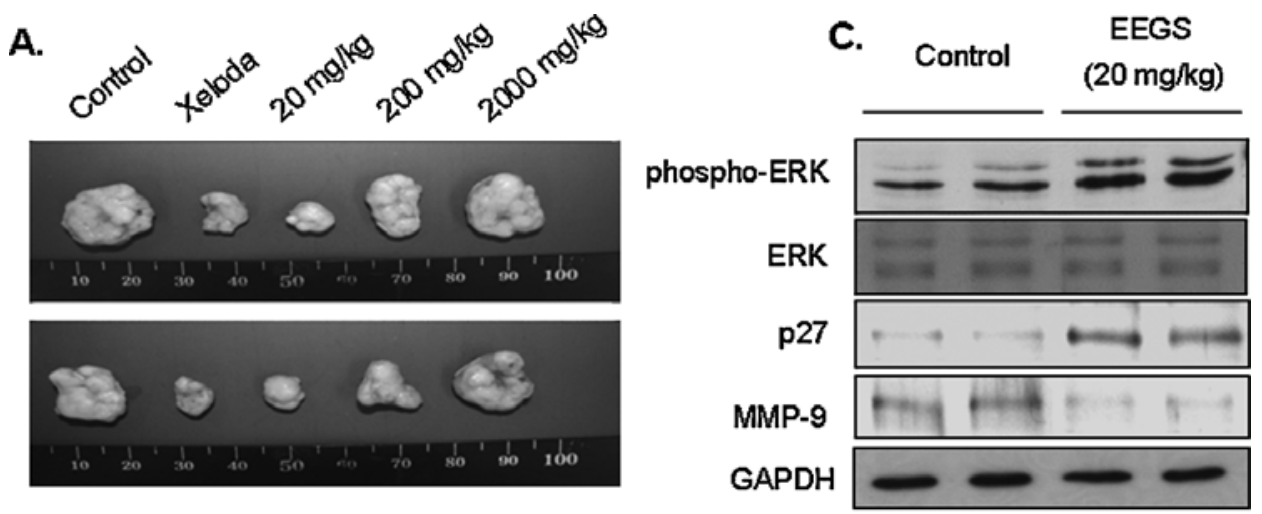

B.

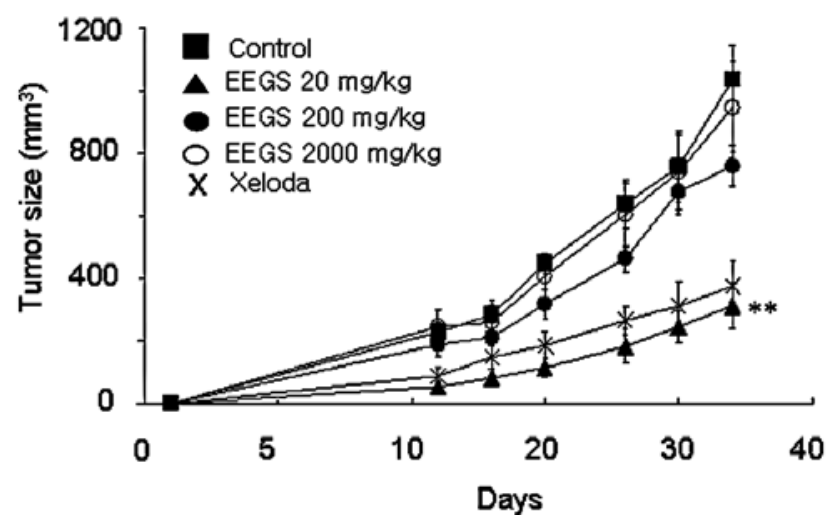

Figure 7. The effects of EEGS on the growth of HCT116 cells in nude mice. Gross appearance (A) and volume (B) of isolated tumors after treatment with PBS, Xeloda and EEGS. Results are presented as mean \pm SE from three triplicate experiments. ${ }^{* *} \mathrm{P}<0.01$ compared with PBS treatment. (C) Two randomly selected tumor samples $(20 \mathrm{mg} / \mathrm{kg})$ were homogenized and immunoblot analyses were performed to determine the expression of phosphor-ERK1/2, ERK1/2, p27 and MMP-9 expression. The results from representative experiments were normalized to GAPDH expression. 
agents, has become necessary. Of these, various parts of Gleditsia sinensis have been evaluated in China and Korea for potential therapeutic effects (23). The fruits and seeds of Gleditsia sinensis have primarily been used for treating apoplexy, headache, asthma and scabies (24). On the other hand, the thorns are used for the treatment of carbuncle, scabies, suppurative skin diseases and anti-inflammatory effects (23). However, the effect and mechanism responsible for anti-tumor treatment with the thorns of Gleditsia sinensis have not yet been fully clarified. To accomplish this, the present study included in vitro and in vivo experiments using ethanol extracts of Gleditsia sinensis thorns (EEGS) to evaluate its anti-tumor effect and mechanism.

Treatment of HCT116 cells with EEGS (400-1000 $\mu \mathrm{g} / \mathrm{ml})$ resulted in the inhibition of cell growth and increased cell death. The ability of chemopreventive or chemotherapeutic agents to inhibit the growth of cancer cells is linked with blocking the cell-cycle progression at the G2/M checkpoint. In general, the $\mathrm{G} 2 / \mathrm{M}$ transition is regulated by a complex of cell-division cyclins, Cdc2 (CDK1) and a B-type cyclin (25). Protein tyrosine phosphatase, cdc25C, plays the role of a mitotic activator by dephosphorylating cdc $2 / \mathrm{p} 34$, which forms the $\mathrm{Cdc} 2 /$ Cyclin B 1 complexes, thereby permitting cell entry into mitosis (20). Results from studies showing various genetic and epigenetic alterations showed that cdc $2 / \mathrm{p} 34$ kinase activity is enhanced in some human cancers $(25,26)$. Consistently, EEGS treatment resulted in down-regulation of cdc25C, cdc2 and cyclin B1 expression in HT116 colon cancer cells. The results of the present study indicate that EEGS caused G2/M-phase cell cycle arrest together with a decrease in cyclinB1 and $\mathrm{Cdc} 2$, which are involved in cell cycle progression from the $\mathrm{G} 2 / \mathrm{M}$ phase.

Members of the CDKI family of proteins (CDK inhibitors) regulate the kinase activity of $\mathrm{CDK} /$ cyclin complexes, and thereby restrict the G2/M-phase transition (19-21). The important CDKI member p27 is known to be up-regulated by anti-proliferative signals (27). The data demonstrate that an apparent increase in p27 appeared during the G2/M-phase arrest in HCT116 cells treated with EEGS. However, EEGS had no effect on the expression of p21 and p53 as determined by immunoblot analysis. These results suggest that accumulation of p27 induced by EEGS may also be responsible for G2/M-phase arrest in HCT116 cells. To the best of our knowledge, this is the first systematic study examining the involvement of each component of the CKI-cyclin-CDK machinery during EEGS-induced cell-cycle arrest.

MAPK signaling pathways play important roles in regulating the inhibition of cell growth (28). The MAPK cascade consists of a core of three protein kinases such as ERK, p38 MAP kinase and JNK pathways (29). To understand the early signal transduction pathways of EEGS, the potential involvement of the MAPK pathway was examined using ERK, p38 MAP kinase and JNK. Treatment with EEGS induced ERK, JNK and p38 MAP kinase phosphorylation. Previous studies have demonstrated that the MAPK pathway is closely associated with the inhibition of cell growth $(28,30)$ and/or cell cycle regulation $(31,32)$. Because of EEGS-induced p27 expression, the role of MAPK in the regulation of $\mathrm{p} 27$ expression was investigated. To examine the crosslink between the MAPK signaling pathway and p27 regulation, pharmaco- logical inhibitors, such as PD98059, SB203580 and SP600125, were employed. An unexpected noteworthy development in this study was that a significant reduction in EEGS-induced expression of p27 was accomplished only by PD98059 treatment. Treatment of cells with SB203580 and SP600125 had no effect on EEGS-induced p27 expression, under the same experimental conditions (Fig. 5A), suggesting that activation of these two types of kinases is not required for EEGS-induced p27 expression, although EEGS induces both activation of p38 kinase and JNK. The blockade of ERK with PD98059 consistently abolished the EEGS-induced inhibition of cell proliferation and down-regulation of cell cycleassociated proteins, $\mathrm{Cdc} 2$ and $\mathrm{Cdc} 25 \mathrm{c}$. These data provide evidence that ERK is a key mediator of the EEGS-induced inhibition of cell growth. The ERK signaling pathway reportedly sends dual signals: a survival signal, and a signal inhibiting cell growth via suppression of the cell cycle progression $(28,30-33)$. The present study suggests that activation of ERK signaling is involved in the EEGS-induced inhibition of cell growth due to the induction of p27 in HCT116 cells. This study demonstrated the first evidence of an association between the ERK signaling pathway and regulation of p27 in the EEGS-induced inhibition of cell growth.

Matrix metalloproteinase-9 (MMP-9) is a zinc-dependent extracellular protease that regulates metastatic progression in colon cancer $(34,35)$. Recent studies provide evidence that TNF- $\alpha$ enhances MMP-9 expression via activation of NF- $\mathrm{KB}$ in colon cancer cell lines (36). Therefore, we further investigated the effects of the EEGS on MMP-9 regulation in HCT116 cells in response to TNF- $\alpha$. In TNF- $\alpha$-treated HCT116 cells, EEGS inhibited the TNF- $\alpha$-stimulated MMP-9 expression at the protein level using both zymographic and immunoblot analyses. However, treatment with EEGS had no effect on the expression of MMP-2. Numerous studies have demonstrated that TNF- $\alpha$ enhanced transcriptional MMP-9 promoter activity through AP-1 and NF-кB in several cell lines $(18,37,38)$. In the same line with the zymography and immunoblot analyses, our data from the present study showed that EEGS effectively suppressed MMP-9 promoter activity. We next attempted to determine the effect of EEGS on the TNF- $\alpha$-induced binding activities of $\mathrm{AP}-1$ and $\mathrm{NF}-\kappa \mathrm{B}$ in MMP-9 expression in HCT116 cells. Cells treated with EEGS showed a marked decrease in both AP-1 and NF- $\mathrm{KB}$ binding activities in response to TNF- $\alpha$ in HCT116 cells. Theses results showed that inhibition of TNF- $\alpha$-induced MMP-9 production in vitro by EEGS was directly linked to the decrease of both AP-1 and $\mathrm{NF}-\kappa \mathrm{B}$ binding activities in HCT116 cells.

Furthermore, EEGS effectively suppressed the growth of HCT116 cells implanted in mice. The present in vivo study also demonstrated that EEGS treatment resulted in the upregulation of ERK phosphorylation and p27 expression and decreased MMP-9 expression. Treatment with the highest doses of EEGS did not decrease body weight, in comparison with the control mice. However, additional studies are required to clearly elucidate the relationship between the molecular mechanism underlying apoptosis related to signaling cascades and animal study with EEGS.

In summary, results of the present study show that the inhibition of cell growth induced by EEGS appears to be linked 
to activation of ERK via p27-mediated G2/M-phase cell cycle arrest. In addition, EEGS potently inhibits TNF- $\alpha$-induced MMP-9 expression by suppressing NF- $\mathrm{KB}$ and AP-1 binding activities. Finally, EEGS suppressed the in vivo growth of HCT116 cells, which was associated with changed levels of ERK, MMP-9 and p27 expression. These results suggest that EEGS can be effectively used in therapeutic application for the treatment of colon cancer, but further detailed in vivo study is needed to clarify the molecular mechanism of this effective EEGS compound.

\section{Acknowledgements}

This study was supported by the Korea Science and Engineering Foundation (KOSEF) grant funded by the Korean government (MEST) (R11-2008-014-01001). This study was also supported partly by Bio Organic Material \& Food Center at Seowon University in 2008, a part of Regional Innovation Center (RIC) program of the Ministry of Knowledge Economy in Republic of Korea.

\section{References}

1. Arber N and Levin B: Chemoprevention of colorectal cancer: ready for routine use? Recent Results Cancer Res 166: 213-230, 2005.

2. Kinzler KW and Vogelstein B: Lessons from hereditary colorectal cancer. Cell 87: 159-170, 2006.

3. Samowitz WS, Curtin K, Ma KN, Edwards S, Schaffer D Leppert MF and Slattery ML: Prognostic significance of p53 mutations in colon cancer at the population level. Int J Cancer 99: 597-602, 2002

4. Himelstein BP, Canete-Soler R, Bernhard EJ, Dilks DW and Muschel RJ: Metalloproteinases in tumor progression: the contribution of MMP-9. Invasion Metastasis 14: 246-258, 1994.

5. Igney FH and Krammer PH: Death and anti-death: tumour resistance to apoptosis. Nat Rev Cancer 2: 277-288, 2002.

6. Sebolt-Leopold JS, Dudley DT, Herrera R, Becelaere KV, Wiland A, Gowan RC, Tecle H, Barrett SD, Bridges A, Przybranowski S, Leopold WR and Saltiel AR: Blockade of the MAP kinase pathway suppresses growth of colon tumors in vivo. Nat Med 5: 810-816, 1999.

7. Agarwal R, Agarwal C, Ichikawa H, Singh RP and Aggarwal BB: Anticancer potential of silymarin: from bench to bed side. Anticancer Res 26: 4457-4498, 2006.

8. Lu J, Kim SH, Jiang C, Lee H and Guo J: Oriental herbs as a source of novel anti-androgen and prostate cancer chemopreventive agents. Acta Pharmacol Sin 28: 1365-1372, 2007.

9. Ahn DK: Illustrated Book of Korean Medicinal Herbs. Kyohak Publishing Co, pp628, 2003.

10. Lim JC, Park JH, Budesinsky M, Kasal A, Han YH, Koo BS, Lee SI and Lee DU: Antimutagenic constituents from the thorns of Gleditsia sinensis. Chem Pharm Bull 53: 561-564, 2005.

11. Zhou L, Li D, Wang J, Liu Y and Wu J: Antibacterial phenolic compounds from the spines of Gleditsia sinensis Lam. Nat Prod Res 21: 283-291, 2007.

12. Li WH, Zhang XM, Tian RR, Zheng YT, Zhao WM and Qiu MH: A new anti-HIV lupane acid from Gleditsia sinensis Lam. J Asian Nat Prod Res 9: 551-555, 2007.

13. Shin TY and Kim DK: Inhibitory effect of mast cell-dependent anaphylaxis by Gleditsia sinensis. Arch Pharm Res 23: 401-406, 2000.

14. Park E and Shin MJ: Anti-inflammatory activity of aqueous extract from Gleditsiae Spina. Arch Pharm Res 37: 124-128, 1993.

15. Tang WK, Chui CH, Fatima S, Kok SH, Pak KC, Ou, TM, Hui KS, Wong MM, Wong J, Law S, Tsao SW, Lam KY, Beh PS, Srivastava G, Ho KP, Chan AS and Tang JC: Inhibitory effects of Gleditsia sinensis fruit extract on telomerase activity and oncogenic expression in human esophageal squamous cell carcinoma. Int J Mol Med 19: 953-960, 2007.

16. Zhong L, Qu G, Li P, Han J and Guo D: Induction of apoptosis and G2/M cell cycle arrest by Gleditsioside E from Gleditsia sinensis in HL-60 cells. Planta Med 69: 561-563, 2003.
17. Moon SK, Jung SY, Choi YH, Lee YC, Patterson C and Kim CH: PDTC, metal chelating compound, induces G1 phase cell cycle arrest in vascular smooth muscle cells through inducing p21Cip1 expression: involvement of p38 mitogen activated protein kinase. J Cell Physiol 198: 310-323, 2004

18. Moon SK, Cha BY and Kim CH: ERK1/2 mediates TNF-alphainduced matrix metalloproteinase- 9 expression in human vascular smooth muscle cells via the regulation of NF-kappaB and AP-1: involvement of the ras dependent pathway. J Cell Physiol 198: 417-427, 2004.

19. Nigg EA: Cyclin-dependent protein kinases: key regulators of the eukaryotic cell cycle. Bioessays 17: 471-480, 1995.

20. Gautier J, Solomon M, Booher R, Bazan J and Kirschner M: $\mathrm{Cdc} 25$ is a specific tyrosine phosphatase that directly activates Cdc2. Cell 65: 197-211, 1991.

21. Sherr CJ: Cancer cell cycles. Science 274: 1672-1677, 1996.

22. Panchal RG: Novel therapeutic strategies to selectively kill cancer cells. Biochem Pharmacol 55: 247-252, 1998.

23. Ha HH, Park SY, Ko WS and Kim Y: Gleditsia sinensis thorns inhibit the production of NO through NF-kappaB suppression in LPS-stimulated macrophages. J Ethnopharmacol 118: 429434, 2008.

24. Dai Y, Chan YP, Chu LM and Bu PP: Antiallergic and antiinflammatory properties of the ethanolic extract from Gleditsia sinensis. Biol Pharm Bull 25: 1179-1182, 2002.

25. Taylor WR and Stark GR: Regulation of the G2/M transition by p53. Oncogene 20: 1803-1815, 2001.

26. Graves PR, Yu L, Schwarz JK, Gales J, Sausville EA, O'Connor PM and Piwnica-Worms H: The Chk1 protein kinase and the $\mathrm{Cdc} 25 \mathrm{C}$ regulatory pathways are targets of the anticancer agent UCN-01. J Biol Chem 275: 5600-5605, 2000.

27. Polyak K, Kato JY, Soloman MJ, Sherr CJ, Massague J, Roberts JM and Koff A: p27Kip1, a cyclin-Cdk inhibitor, links transforming growth factor-beta and contact inhibition to cell cycle arrest. Gene Dev 8: 9-22, 1994.

28. Xia Z, Dickens M, Raingeaud J, Davis RJ and Greenberg ME: Opposing effects of ERK and JNK-p38 MAP kinases on apoptosis. Science 270: 1326-1331, 1995.

29. Pearson G, Robinson F, Beers Gibson T, Xu BE, Karandikar M, Berman K and Cobb MH: Mitogen-activated protein (MAP) kinase pathways: regulation and physiological functions. Endocr Rev 22: 153-183, 2001.

30. Wang X, Martindale JL and Holbrook NJ: Requirement for ERK activation in cisplatin-induced apoptosis. J Biol Chem 275: 39435-39443, 2000.

31. Chambard JC, Lefloch R, Pouyssegur J and Lenormand P: ERK implication in cell cycle regulation. Biochim Biophys Acta 1773: 1299-1310, 2007.

32. Malumbres M, Pérez De Castro I, Hernández MI, Jiménez M, Corral $\mathrm{T}$ and Pellicer A: Cellular response to oncogenic ras involves induction of the Cdk4 and Cdk6 inhibitor p15(INK4b). Mol Cell Biol 20: 2915-2925, 2000.

33. Boulton TG, Nye SH, Robbins DJ, Ip NY, Radziejewska E, Morgenbesser SD, DePinho RA, Panayotatos N, Cobb MH and Yancopoulos GD: ERKs: a family of protein-serine/threonine kinases that are activated and tyrosine phosphorylated in response to insulin and NGF. Cell 65: 663-675, 1991.

34. Lubbe WJ, Zhou ZY, Fu W, Zuzga D, Schulz S, Fridman R Muschel RJ, Waldman SA and Pitari GM: Tumor epithelial cell matrix metalloproteinase 9 is a target for antimetastatic therapy in colorectal cancer. Clin Cancer Res 12: 1876-1882, 2006.

35. Roeb E, Dietrich CG, Winograd R, Arndt M, Breuer B, Fass J, Schumpelick V and Matern S: Activity and cellular origin of gelatinases in patients with colon and rectal carcinoma differential activity of matrix metalloproteinase-9. Cancer 92: 2680-2691, 2001

36. Choo MK, Sakurai H, Koizumi K and Saiki A: Stimulation of cultured colon 26 cells with TNF- $\alpha$ promotes lung metastasis through the extracellular signal-regulated kinase pathway. Cancer Lett 230: 47-56, 2005.

37. Bond M, Rosalind P, Fabunmi P, Baker AH and Newby AC: Synergistic upregulation of metalloproteinase- 9 by growth factors and inflammatory cytokines: an absolute requirement for transcription factor NF-kappa B. FEBS Lett 435: 29-34, 1998.

38. Sato H, Kita M and Seiki M: v-Src activates the expression of 92-kDa type IV collagenase gene through the AP-1 site and the GT box homologous to retinoblastoma control elements, A mechanism regulating gene expression independent of that by inflammatory cytokines. J Biol Chem 268: 23460-23468, 1993. 